\title{
НАША ПРОФЕССИЯ
}

УДК 025.3:37

Э. Р. Сукиасян

РГБ

\section{«Штучный товар». \\ О подготовке специалистов \\ в области современной каталогизации}

\begin{abstract}
Статья посвящена проблемам подготовки каталогизаторов высокой квалификации. Автор считает, что их нужно готовить по заявкам библиотек, специально отбирая кандидатов и заключая с ними договоры. Подчёркнуто, что эта работа требует особой ответственности. Рассказано об отборе и подготовке каталогизаторов высокой квалификации в США. Обращено внимание на то, что объём знаний и умений каталогизаторов такого уровня в России должен быть большим, поскольку в него следует включить как международные, так и национальные требования. По мнению автора, прежде чем перестраивать работу по каталогизации, необходимо серьёзно обсудить организационные и программно-методические вопросы.
\end{abstract}

Ключевые слова: каталогизация, каталогизатор высокой квалификации, компетенции.

UDC 025.3:37

\section{Eduard Sukiasyan}

Russian State Library, Moscow, Russia

\section{Rare specialists. \\ On the training of experts in the field of modern cataloging}

Article on the problems of training of cataloguers of high qualification - experts in the field of modern cataloging. Author believes that they need to be prepared for library applications, specifically selecting candidates and concluding agreements with them. Work requires special responsibility. It is told about the selection and preparation of cataloguers of high qualification in the USA. The volume of knowledge and skills of catalogers of this level in Russia will be great, as it will include both international and national requirements.

Keywords: cataloging, cataloguer, training of highly qualified library staff, collection development. 
The fact that good catalogers are precious stones, I often recalled during those years, when the we were living with the expectation of the "manna of heaven" from joining the OCLC and trying to implement the Russian center of cooperative cataloguing project, and when we naively hoped to get a quick result from the Bologna process and the subsequent struggle for competences. To achieve this, it is necessary to achieve a consensus in understanding the underlying principles, not the training programs, but primarily the selection of candidates. I think that our selection should be competitive. The candidate must know where he/she will work, in what capacity, and responsibility. Wages should not be determined by the graduation certificate, but by the real benefits that the specialist brings to library. If the education of a cataloger is paid for by a library, then he/she feels his/her duties. For example: to work in this library for a certain period (I think, at least 3-5 years). The library should guarantee work in that position and with those duties that were signed upon (rather than using a cataloging specialist, for example, in the recruitment service or as a deputy director). In turn, the one who was prepared at the expense of the library, in case of dismissal is obliged to pay the amount spent on his training. It is necessary to recognize: if the cataloguer does not work for three years (for example, being on maternity leave), she almost completely loses her qualification. I believe that in order to recover after a long break in the same position it is necessary to pass a refresher course, it can be remotely. List of competences for the Russian cataloguer should start with the knowledge of English. Here is the list of the cataloguer competences: 1. Russian rules of cataloging; 2. Classification systems. LBC, UDC, State index of subject headings; 3. Systems of subjectization: authority file of the National Library of Russia; 4. Cataloging formats: MARC21, UNIMARC, RUSMARC; 5. National authority files; 6. Practical work (at the professional level) with the catalogs, systems and databases of the Russian state library, the National library of Russia; 7. Practical work with the LIBNET Center catalogs.

Выражение «штучный товар» прозвучало в заключительный день работы Ежегодного совещания руководителей федеральных и центральных региональных библиотек России (18-19 окт. 2016 г.) в выступлении генерального директора ГРБ А. И. Вислого: так Александр Иванович назвал каталогизаторов высокой квалификации - представителей особой и трудной профессии. А ведь их нигде не готовят. Никто не ожидал услышать подобное, кто-то в зале громко произнёс: «Накипело».

Это выражение - «штучный товар» - я впервые употребил в 1987 г. в статье в нашем журнале (НТБ. - 1987. - № 3. - С. 28-34) и потом использовал неоднократно. О том, что хорошие каталогизаторы - штучный товар, 
я не раз напоминал в те годы, когда вся страна жила ожиданием «манны небесной» от вступления в OCLC. Об этом же говорил, когда пытались реализовать проект РЦКК. И годы спустя, когда все наивно надеялись получить быстрый результат от Болонского процесса и последующей борьбы за «компетентности». Неоднократно поднимал этот вопрос и на конференции «Крым».

«Штучные» каталогизаторы с неба не падают. Их нужно выращивать. Для этого необходимо добиться консенсуса в понимании исходных принципов, причём не программы обучения, а прежде всего - отбора кандидатов. Полагаю, что у нас отбор должен быть конкурсным. Кандидат должен знать, где он будет работать, в каком качестве, с какой степенью ответственности. Платить заработную плату надо не за «корочки», а за реальную выгоду, которую приносит специалист.

Меня однажды спросили, о какой ответственности идёт речь. Разве не директор библиотеки отвечает за всё? К сожалению, в условиях «распределённо-разделённой» ответственности (правильнее - безответственности) у нас никто ни за что не отвечает. Повторюсь (многократно писал об этом): до тех пор, пока сумма надбавок к окладу у нас не будет определяться результатами работы, не появится ответственность. Все знают: премии распределяют по всем «головам», как правило - пропорционально должностному окладу, надбавки - по достигнутым в прошлом году показателям (чего? Оплаты труда). Малейшее нарушение такого «порядка» приведёт к жалобе. Так будет до тех пор, пока мы не введём self-evaluation (дословно: самооценка). Здесь главное слово - self. Вы должны сами оценивать себя и свои достижения, сравнивая показатели работы в истекающем году с тем, что было запланировано год назад.

Если подготовка «штучного» каталогизатора оплачивается библиотекой, которая заинтересована в его работе, то он чувствует свои обязанности. Например, такие: проработать в этой библиотеке определённый срок (думаю, не менее 3-5 лет). Все тонкости обязательств фиксируются в проработанном юристами договоре. Библиотека должна гарантировать работу на той позиции и с теми обязанностями, которые предполагались (а не использовать специалиста-каталогизатора, например, в службе комплектования или в качестве заместителя директора). В свою очередь, тот, кого готовили за счёт библиотеки, в случае увольнения обязан выплатить сумму, потраченную на его обучение. Например, если сотрудница приносит справку с места работы супруга «о переводе в другую местность».

Необходимо признать: если каталогизатор не работает три года (например, находясь в декретном отпуске), он почти полностью теряет свою квалификацию. Считаю, что для восстановления после большого перерыва в 
той же позиции необходимо пройти курс повышения квалификации, можно дистанционно. Но с одним условием - нужно выполнить все задания, зачётные контрольные и выпускные письменные работы. За три года в каталогизации может многое измениться, прежде всего - в нормативных пособиях, с которыми работает каталогизатор (ниже я их перечислю).

Как готовят «штучных» каталогизаторов в США? Сначала надо сказать, что в Америке не следуют европейским Болонским принципам. Путь от бакалавра (с университетским дипломом) к магистру с дипломом Библиотечной школы обязательно прерывается на 3-5 лет. Необходимо сначала доказать, что ты - библиотекарь. И если ты нужен библиотеке как профессионал, тебе окажут помощь - и не только материальную (оплатят обучение). Бесплатного образования взрослых в США давно нет. Есть много грантов, способов накопления средств для учёбы. Например, служба в американский армии, как известно, не является обязательной и потому хорошо оплачивается.

Дети сотрудников университета освобождаются от платы за обучение в нём. Можно подумать, что такой привилегией воспользуются многие. Оказалось - всего 7-9\%. Мне объяснили: у них так не принято. Молодёжь выбирает другие города и кампусы. От «вечернего» обучения американцы давно отказались. Они предпочитают учиться утром, а работать вечером (большинство библиотек работает круглосуточно). А заочную форму обучения заменяет работа в выгодном режиме part time: 20 часов в неделю работаешь, а 20 - учишься.

Чтобы стать каталогизатором-специалистом, следует не менее 5-6 лет поработать рядовым каталогизатором, получить степень магистра в Библиотечной школе (очень важно правильно определить тему магистерской диссертации), включиться в работу в соответствующем профессиональном сообществе - в Американской библиотечной ассоциации, а также в региональной библиотечной ассоциации. Необходимо сделать что-то значимое, например проанализировать опыт, динамику статистики, выступить с докладом, напечатать пару-тройку статей. Хорошо бы ещё закончить какиелибо курсы, получить сертификаты, предоставляющие права пользования той или иной системой, например OCLC. (OCLC можно пользоваться всем, в том числе и читателям. Но если вы закончили специальные курсы, то потенциальные возможности OCLC раскроются гораздо глубже.) Особо приветствуется изучение языков. В США никаких «языковых надбавок» не платят: эти знания предусмотрены требованиями к квалификации на определённой должности.

Очень хорошо, если вы поступите в докторантуру и защитите диссертацию. А если вам предложили руководить подразделением, осуществляю- 
щим каталогизацию, можно (в докторантуре или вне её) подготовить и защитить диссертацию на степень доктора по менеджменту (Business administration) или управлению персоналом (Personal administration). Сейчас такие профильные докторские защищаются в библиотечных школах США.

Осталось получить ещё один документ (и соответствующую надбавку) сертификат специалиста. Если вы уже всё знаете - оформляйте документы, собирайте рекомендации и характеристики. В отличие от нашей страны, в США характеристика-рекомендация считается нормой. Рекомендации носят личный характер, а рекомендующий берёт на себя часть ответственности. У меня, например, несколько раз просили охарактеризовать моего ученика, выпускника Высших библиотечных курсов, оказавшегося в США.

Одним словом, если чувствуете, что надо что-то дополнительно изучить или освоить, - изучайте и осваивайте.

О том, что вы перешли в категорию специалистов, сообщают в журналах: публикуется объявление с портретом. Все члены Американской библиотечной ассоциации получают журнал «American Libraries» («Американские библиотеки»), из которого узнают о новых назначениях, а также о других приятных (например, премиях) или неприятных (смерть, пожар или наводнение) событиях американской библиотечной жизни.

Раньше в этом журнале публиковалось много объявлений о вакансиях с требованиями. Сами каталогизаторы дают объявления редко, чаще - «обратного свойства» (work search) (специалист хочет переехать и заявляет о своих пожеланиях с подробным описанием опыта работы и компетенций).

Со стажем и опытом работы всё понятно. Многое зависит от места, которое занимает библиотека в системе. Для публичных библиотек определяющий признак - население, для университетских важны разные критерии, для специальных библиотек имеет большое значение профиль: необходимо иметь соответствующие степени. Американцы хотят, чтобы библиотекари могли общаться на национальных языках. В многонациональном НьюЙорке, например, выполнить это пожелание практически невозможно.

Перечислим компетенции каталогизатора высшей квалификации в США:

Правила каталогизации. Новые - RDA (Resource Description and Access) и старые, но пока активно используемые, - AACR2R (AngloAmerican Cataloguing Rules $2^{\text {nd }}$ Revised ed);

Классификационные системы. DDC (Dewey Decimal Classification), LCC (Library of Congress Classification);

Системы предметизации. LCSH (Library of Congress Subject Headings);

Формат каталогизации. MARC21;

Национальные авторитетные файлы; 
Практическая работа (на профессиональном уровне) с каталогами, системами и базами данных OCLC;

Практическая работа (на профессиональном уровне) с каталогами и базами данных Библиотеки Конгресса США и других библиотек США;

Практическая работа с электронными каталогами зарубежных библиотек.

Обратим внимание: никакого функционального разделения труда у каталогизаторов в США, как правило, нет. Объект каталогизации поступает к одному человеку и полностью обрабатывается на одном рабочем терминале. В необходимых случаях предварительная работа (например, поиск в базах данных и каталогах, уточнение формы заголовка, перевод заглавия и аннотирование и пр.) выполняется техническими помощниками.

Список компетенций для российского каталогизатора нужно начать со знания английского языка. Это необходимо для профессиональной работы с перечисленными выше инструментами. Во многих случаях дешевле найти запись и «перестроить» её для наших каталогов, чем проводить обработку самостоятельно.

Приведём список компетенций российского каталогизатора:

Российские правила каталогизации;

Классификационные системы: Библиотечно-библиографическая классификация, Универсальная десятичная классификация, полное русское издание, Государственный рубрикатор НТИ;

Системы предметизации: авторитетный файл РНБ;

Форматы каталогизации: MARC21, UNIMARC, RUSMARC;

Национальные авторитетные файлы;

Практическая работа (на профессиональном уровне) с каталогами, системами и базами данных РГБ, РНБ и других библиотек страны;

Практическая работа с каталогами Центра ЛИБНЕТ.

И это далеко не всё. Если мы хотим серьёзно перестроить каталогизацию в нашей стране, необходимо обсудить организационные и программнометодические вопросы. И только потом будем составлять планы и программы.

10-15 лет назад я обязательно бы участвовал в этой работе, знал, кого привлечь. Сегодня остались силы лишь на то, чтобы поставить вопрос, привлечь внимание, принять участие в обсуждении.

Выражение «штучный товар» (an object of great rarity) - это антоним массового товара. В 1990 г. в Питтсбурге меня именно так назвали, объяснив: в США всего десяток специалистов, которые читают курс по истории и теории классификации; они ездят по библиотечным школам в качестве visiting professor. Мне предложили остаться, войти в штат преподавателей... 
Сегодня ситуация изменилась: в США стали докторами и получили профессорские звания выходцы из Индии, обучавшиеся в Бангалоре. Воспитанники школы великого Ранганатана уже «захватили» американский и азиатский континенты, работают в Африке, Европе.

Скоро и нам ничего не останется, кроме как приглашать индийских профессоров...

Eduard Sukiasyan, Cand. Sc. (Pedagogy), Associate Professor, Sector Head of the Chief Editorial Board of Library Bibliographical Classification (BBK Research Center), Russian State Library;

sukiasyaner@rsl.ru

3/5, Vozdvizhenka st., 119019 Moscow, Russia 